\title{
LA POESÍA AFROPERUANA DE MÓNICA CARRILLO ZEGARRA COMO PROTESTA: UNA LECTURA DEL FEMINISMO NEGRO Y DECOLONIAL EN "JUGUEMOS EN LA JUNGLA"
}

\author{
A POESIA AFRO-PERUANA DE MÓNICA CARRILLO \\ ZEGARRA COMO PROTESTO: UMA LEITURA \\ DO FEMINISMO NEGRO E DESCOLONIAL EM \\ "JUGUEMOS EN LA JUNGLA"
}

Paulo Valente ${ }^{1}$

[https://orcid.org/0000-0002-2223-8146]

DOI: 10.30612/raido.v15i38.14824

RESUMO: En este artículo propongo una lectura del poema "Juguemos en la jungla", de la poeta afroperuana Mónica Carrillo Zegarra, publicado originalmente en el libro Unícroma, en 2007, en la ciudad de Lima, y posteriormente en versión digital, en 2015, por el Instituto Cervantes. Esta lectura se dedica a destacar la ironía del yo lírico que establece distinciones definitivas entre la experiencia de mujeres blancas y negras, como una crítica al sujeto universal del feminismo estándar. También señalo el proceso de construcción de dicho poema como herramienta de contraposición a la historia canónica que trató de silenciar ese personaje específico, la negra. Para tanto, utilizo textos teóricos de Gayatri Spivak (1998), Chandra Mohanty (2008), Ochy Curiel (2010), María Lugones (2011), Grada Kilomba (2019) y otros.

Palavras-chave: Feminismos negros y decolonial; racismo; mujeres negras, raza y género.

ABSTRACT: In this article I propose a reading of the poem "Juguemos en la jungla", by the Afro-Peruvian poet Mónica Carrillo Zegarra, originally published in the book Unícroma, in 2007, in the city of Lima, and later in a digital version, in 2015, by the Cervantes Institute. This reading is dedicated to highlighting the irony of the lyrical voice that establishes definitive distinctions between the experience of black and white women, as a critique of the universal subject of standard feminism. I also point out the process of construction of the poem as a tool of opposition to the canonical history that tried to silence that specific character, the black woman. For this, I use theoretical texts by Gayatri Spivak (1998), Chandra Mohanty (2008), Ochy Curiel (2010), María Lugones (2011), Grada Kilomba (2019) and others.

Keywords: Black and decolonial feminisms; racism; black women, race and gender.

1 Universidade Federal de Santa Catarina (UFSC). 
“¿Soy acaso negra?" - me dije ¡SÍ!

“¿Qué cosa es ser negra?" ¡Negra!

Y yo no sabía la triste verdad que aquello escondía. ¡Negra!

Y me sentí negra, ¡Negra!

Como ellos decían ¡Negra!

Y retrocedí ¡Negra!

Como ellos querían ¡Negra!

Y odié mis cabellos y mis labios gruesos

y miré apenada mi carne tostada

Y retrocedí ¡Negra!

Y retrocedí...

¡Negra! ¡Negra! ¡Negra! ¡Negra! (CRUZ, Victoria Santa, 2021, s.p)

I am not the 'Other,' but the self, not the object, but the subject, I am the describer of my own history, and not the described. Writing therefore emerges as a political act. (KILOMBA, 2010, p. 12)

Grada Kilomba (2010), en el libro Plantation memories, dedica las páginas iniciales a debatir la importancia de contraponerse a la Historia canónica, de no ser 'el otro, sino el yo', de escribir discursos otros en los cuales las voces de sujetos marginados resuenen, de donde puedan estos sujetos contar bajo otra perspectiva una historia que fue sistemáticamente borrada de los manuales escolares, además de invisibilizada en los discursos oficiales occidentales. Es decir, la escritura es un arma cargada de munición precisa que le otorga a las voces silenciadas por la de los vencedores (cf. Benjamín, 2012) un modo de inserirse en la Historia, más aún, de interrumpirla, remodelarla. Escribir es un acto de autoridad, de creación y un registro de una realidad de personajes históricos que no se oían. Cuando el otro del discurso oficial escribe, descoloniza el pensamiento occidental legitimado y recurre a una memoria que urge que se la cuente.

En el ambiente académico, los estudios de género y de raza al lado de los estudios culturales han producido un cambio interesante de mirada hacia grupos que casi nunca estuvieron presentes en los discursos mayoritarios, en que, no raro, el poder social de los vencedores está puesto como marca indeleble. Son narrativas y textos en versos que registran un pasado glorioso de los pueblos europeos, sus viajes, supuestos descubrimientos, la llegada a América, creando una imagen positiva del colonizador, en suma, un aventurero, conquistador, sujeto de su propia historia que mira a los demás y, desde un lugar privilegiado, creyéndose en una misión especial, les nombra e impone un espacio muy específico de vida e identidad.

Las identidades de los sujetos no blancos, colonizados por el sistema de la colonización / modernidad, en este sentido, son siempre el otro / la otra, o sea, sobre quien se habla. Asimismo, la Literatura puede ser leída como mecanismo para mantener el poder discursivo e imponente, representación del orden vigente, e idealización de una costumbre en vigor, o simplemente la manutención del status quo de la voz 
impuesta del sujeto que se cree, se lee y se representa como universal: el hombre, blanco, europeo, heterosexual. Sin embargo, puede ser una herramienta poderosa para crear otras posibilidades, promover otros discursos y contar lo que las voces colonizadoras trataron de silenciar. Al fin y al cabo, la literatura es un espacio de debates, una arena en que discursos se enfrentan debatiendo y representando la sociedad misma que los produce.

Texto como los de Mónica Carrillo Zegarra son, de hecho, un registro en que la autora escribe y repiensa la sociedad a partir de esas voces que siempre estuvieron en el hondo de la escena literaria. La escritora afro peruana se suma a otras mujeres negras latinoamericanas que registran no solamente los traumas del racismo y del sexismo en las sociedades contemporáneas suyas, pero, igualmente hacen hincapié en la búsqueda de un origen, de rutas que ayuden a comprender el proceso colonial que produjo sus cuerpos marginados. También de Perú, destaco la voz de la folclorista y poeta Victoria Santa Cruz; de Brasil, las de Conceiçăo Evaristo y Cristiane Sobral; de Cuba, la prosa de Teresa Cárdenas. Son todas mujeres negras que escriben la historia de su pueblo - y se escriben en la Historia, a la vez - como resistencia contra el poder hegemónico burgués, blanco, racista, heredero de la colonización europea.

Las producciones firmadas por esas mujeres tienen en común una preocupación en tejer juicios a la universalidad del referente mujer que, según concluyen, se olvidó de pluralizar su significado. Son textos que nos ofrecen críticas desde dentro del feminismo estándar, cuando se lo piensa en relación con otros marcadores sociales surgidos con la colonización ocurrida en los países latinoamericanos como excusa a la producción de la modernidad europea, a partir de finales del siglo XV.

Chandra Mohanty, en el texto Bajo los ojos de occidente. Academia Feminista y discurso colonial (2008), observa que las feministas occidentales al producir un sujeto discursivo 'mujer' se vislumbran en una unicidad y esperan que las mujeres del tercer mundo también sean una otra categoría homogénea. Esa forma de comprender los hechos ya crea, o mejor, fundamenta una jerarquía social y política sufriendo los impactos de la colonización, y manteniendo una diferencia entre sujetos superiores e inferiores, pautas supuestamente universales y otras menos importantes porque no les alcanza a todas las mujeres.

La colonización se ha utilizado para caracterizar todo, desde las más evidentes jerarquías económicas y políticas hasta la producción de un discurso cultural particular sobre lo que se llama "tercer mundo". Sin importar cuán sofisticado o problemático sea su uso como construcción explicativa, la colonización en casi todos los casos implica una relación de dominación estructural y una supresión, muchas veces violenta, de la heterogeneidad del sujeto o sujetos en cuestión. (MOHANTY, 2008, p. 2, énfasis suyo)

La supresión violenta a que se refiere Mohanty (2008) ayuda a erigir, a dar fundamento a un movimiento feminista que estuvo históricamente ajeno a las pautas de esas mujeres negras, cuyas voces nunca nadie las escuchó en serio ${ }^{2}$. El texto de Mohanty (2008), originalmente de los años ochenta, está en un contexto en que diversas

2 A ese respeto, sugiero los textos de Angela Davis (1983), bell hooks (1984) y de la brasileña Lélia Gonzales (1988). Referencias completas al final del artículo. 
teóricas feministas propusieron cambios al movimiento, produciendo autocríticas, se puede destacar, en este sentido, las obras fundantes de Judith Butler, Adrienne Rich, Monique Wittig, Gloria Anzaldúa, bell hooks, Sueli Carneiro y Lélia Gonzales. Todas mujeres que se preocuparon en pensar la agenda feminista, los perjuicios de género, pero atravesados por otros marcadores, como los de raza, clase, geografías, etc.

Mohanty (2008), quiere aclarar que había una concepción de mujer discursiva que no siempre estaba próxima al entorno de mujeres reales, o sea, que no había una correspondencia inmediata entre sujetos discursivos de la agenda feminista y sujetos históricos que tal movimiento representaba.

La conexión entre las mujeres como sujetos históricos y la representación de Mujer producida por los discursos hegemónicos no es una relación de identidad directa, ni una relación de correspondencia o simple implicación. Se trata de una relación arbitraria construida por culturas particulares. (MOHANTY, 2008, p. 3)

El texto de Mohanty (2008) destaca la necesidad no de romper del todo con las generalizaciones, una vez que a veces son necesarias a la organización social, inclusive de los sujetos marginados, pero que sean específicas y adecuadas a la realidad de esas mujeres, propuestas por ellas, pensadas según sus necesidades, articulando experiencias e identidades como estrategias políticas de acción en el mundo.

Los discursos literarios pueden inserirse ahí como una estrategia discursiva también al servicio de la producción y representación de otras formas de ser mujer, rompiendo con un conjunto de relaciones arbitrarias, manifestando ideologías no canónicas, visiones distintas del mundo, modos otros de ser mujer. Además, los discursos de poetas afrolatinoamericanas, como Mónica Carrillo Zegarra, pone de relieve las distinciones del género vivido por mujeres blancas y el vivido por mujeres negras.

¿En qué medida el color direcciona distintas experiencias para esas dos actrices sociales, aunque vivan el género femenino? Lo que idealiza el yo lírico de "Juguemos en la jungla", por ejemplo, es, al fin y al cabo, dar fe de que mismo que sea el género el marcador social que ayude a comprender las jerarquías entre sujetos leídos como hombres en contra otros leídos como mujeres, la raza también atraviesa esa vivencia y añade nuevos contornos, inteligibles socialmente, que siguen distinguiendo estos cuerpos en el mundo y provocando nuevas jerarquías.

Hazel Carby (2012), a ese respeto, en el texto "Mujeres blancas, jescuchad! El feminismo negro y los límites de la hermandad femenina", en la colectánea Feminismos Negros, de Mercedes Jabardo (org.), señala que:

La historia ha construido nuestra sexualidad y nuestra feminidad alejándolas de las cualidades atribuidas a las mujeres blancas, en tanto que objetos valorados del mundo occidental. También hemos sido definidas con términos que están por debajo de lo humano. Nuestra continua lucha con la historia comenzó cuando ésta nos «descubrió». (CARBY, 2012, p. 209-210. Énfasis suyo)

Carby (2012) plantea que el racismo y el sexismo son similares en el sentido de que se construyen con base en referentes naturales y biológicos para erigir un tratamiento social diferenciado a determinados cuerpos en sociedades racializadas desde una mirada sobre los signos corporales, fenotipos y la anatomía humana. Es, pues, una 
excusa para limitar determinados espacios muy bien trazados a que estos cuerpos puedan acceder y representar socialmente. Cuando determina que la lucha de mujeres negras empezó justo en el momento en que fueron descubiertas, hace hincapié en que la Historia, esa con la mayúscula, la europea, se cree la única posibilidad de existir, de ahí que apenas pudieron existir efectivamente cuando las encontró y las puso como algo semejante a un animal, 'por debajo de lo humano', como puntea.

La llegada del colonizador al continente americano, así, crea la moderna ficción de las razas para mejor controlar los sujetos y las sociedades colonizadas. El europeo se jacta de su descubierta y diseña una forma de ser / existir en esta sociedad nueva, excluyendo las culturas locales, los modos de coexistir de esa población indígena que aquí vivía. Posteriormente, para explorar mejor la región, recurre a la práctica de la esclavitud de sujetos africanos. Para mantener esa ideología dominante en el continente y sostener su pretensa superioridad, llega al denominador de la raza como modo de categorizar estos cuerpos y dominarlos (cf. Quijano, 2014).

María Lugones, en el clásico Hacia un feminismo descolonial (2011), ya aclara que la colonialidad, producto heredero de la colonización como la concibe Quijano (2014), produjo la manutención de las zonas de América Latina y del Caribe como espacio en que estarían los seres no humanos, a servicio de la experiencia de la modernidad europea. Es decir, el colonizador convierte indígenas y negras y negros en seres sirvientes, explotados por el sistema colonial, bajo el signo del racismo, intentando borrar su cultura, lengua, valores, animalizarlos, y los y las clasificar como no humanos. Señalo, sin embargo, que siempre hubo movimientos de resistencia a la colonización.

Concibo la jerarquía dicotómica entre lo humano y lo no humano como la dicotomía central de la modernidad colonial. Comenzando con la colonización de las Américas y del Caribe, se impuso una distinción dicotómica, jerárquica entre humano y no humano sobre los colonizados al servicio del hombre occidental. Estaba acompañada por otras distinciones jerárquicas, entre ellas entre hombres y mujeres. Esta distinción se convirtió en la marca de lo humano y de la civilización. Sólo los civilizados eran hombres y mujeres. Los pueblos indígenas de las Américas y los africanos esclavizados se clasificaban como no humanos en su especie como animales, incontrolablemente sexuales y salvajes. El hombre moderno europeo, burgués, colonial, se convirtió en sujeto/agente, apto para gobernar, para la vida pública, un ser de civilización, heterosexual, cristiano, un ser de mente y razón. La mujer europea burguesa no era entendida como su complemento, sino como alguien que reproducía la raza y el capital mediante su pureza sexual, su pasividad, y su atadura al hogar en servicio al hombre blanco europeo burgués. (LUGONES, 2011, p. 106)

Obviamente que esa clasificación tiene una razón de ser. Con la aprobación de la iglesia cristiana, esta dicotomía postulada en la colonia no era únicamente una separación basada en el color y en los fenotipos de estos sujetos históricos, sino una forma de seguir construyendo una Europa al día de las nuevas tecnologías y valores burgueses de prosperidad, racionalidad y sociedad, mientras que en la América tales valores no llegaban. De ese modo, las creaciones raza y género sirvieron, pues, como una forma de encarcelamiento, determinismo social, disfrazado de biológico.

El europeo, al dibujar la identidad del otro como inferior, está reforzando la suya 
propia y, no gratuita ni casualmente, esta era superior, era humana, de ahí que surge la categoría principal en esta relación: el hombre. Este, blanco, europeo, colonizador, explorador, sin miedo, conquistador. Los demás son cualquier cosa que no alcance esta magnitud y su color / raza sería un indicio de la inferioridad.

Entonces, la modernidad ha sido un modo de organizar el mundo según reglas que difieren las experiencias de los colonizadores de aquellas vividas por los colonizados y las colonizadas. Está puesta bajo un determinismo que trató de crear y posteriormente mantener categorías homogéneas. En este escenario social, la mujer negra acabó por representar una zona múltiple de referencia, como si estuviera en un limbo identitario, sin enterarse del todo de lo que significaba ser lo negro, tampoco la mujer, las otras dos categorías creadas por el dominio del hombre blanco europeo colonizador.

La modernidad organiza el mundo ontológicamente en términos de categorías homogéneas, atómicas, separables. La crítica del universalismo feminista hecha por mujeres contemporáneas de color y del tercer mundo se centra en la idea de que la intersección entre raza, clase y sexualidad y género va más allá de las categorías de la modernidad. Si mujer y negro son términos para categorías homogéneas, atómicas, separables, entonces su intersección nos muestra la ausencia de las mujeres negras en vez de su presencia. Así, ver a mujeres no-blancas es ir más allá de la lógica "categorial". (LUGONES, 2011, p. 106)

Todavía con base en lo que debate Lugones (2011), podemos comprender mejor que un feminismo decolonial y negro está estrechamente relacionado con el origen de la colonización en el continente americano y debe servir como herramienta a que mujeres negras, latinoamericanas, salgan del lugar de objeto discursivo o de explotación de una cultura europea, blanca, y se adueñen de su pasado histórico, vean al mundo contemporáneo no como una continuación no-histórica de los tiempos, sino como una consecuencia de la conformación social, política y económica burguesa, racista que produjo el sistema mundo actual, y de ahí, puedan confrontarlo.

Es decir, la tarea de la feminista descolonial comienza por ver la diferencia colonial, enfáticamente resistiendo su propio hábito epistemológico de borrarla. Al verla, ella ve el mundo con nuevos ojos, y entonces debe abandonar su encantamiento con "mujer", con el universal, y comenzar a aprender acerca de otros y otras que también se resisten ante la diferencia colonial. La lectura opta contra la lectura socio-científica y objetivante, tratando más bien de comprender a los sujetos, su subjetividad activa enfatizada a medida que la lectura busca los locus fracturados en la resistencia a la colonialidad del género en el punto de partida coalicional. (LUGONES, 2011, p. 115.)

La literatura ha sido un espacio para celebrar este locus fracturado y para observación de estas sociedades que fueron colonias de países europeos, como es la peruana, y que después de su liberación política siguieron viviendo bajo un sistema de opresión de clases, raza y género muy semejante al primero impuesto por el colonizador; la colonialidad, que viene a ser, en pocas líneas, la manutención de ideales racistas asimilados por las ex colonias (QUIJANO, 2014).

La colonialidad, a su turno, produce, o más bien mantiene, el racismo y el sexismo vivos en dichos territorios. La filósofa brasileña Sueli Carneiro, a ese respecto señala que, en estos contextos, la mujer negra suele ser el cuerpo más explotado, que sufre con mayor frecuencia las violencias del sistema del dúo colonización / colonialidad, y 
complementa aseverando que, por ello, la mujer negra tuvo de pensar su especificidad mismo dentro del movimiento feminista o del movimiento negro en la América latina, cuando determina que:

Las mujeres negras fueron testigo, en diferentes momentos de su militancia, de cómo la temática específica de la mujer negra fue puesta como secundaria en la supuesta universalidad del género. Esa temática de la mujer negra invariablemente era tratada como subtema de la cuestión general de la mujer.3 (CARNEIRO, 2011, p. 121)

En síntesis, en los países latinoamericanos la experiencia colonial no puede ser olvidada cuando el género esté puesto en cuestión. De ahí que el libro Unícroma, de Mónica Zegarra, es una herramienta política que plantea el contexto del locus a que se refiere Lugones (2011), en el sentido de que sirve como pretexto al revisionismo histórico necesario a que voces silenciadas hablen de un lugar donde fueron puestas, descuidadas, fronterizo. Además, provocan un choque entre la supuesta universalidad discursiva del género y las cuestiones propias de la experiencia negra, como define Carneiro (2011).

En 2007, Mónica publica el libro Unícroma, con éxito entre el público peruano y surge en la escena cultural latinoamericana como una voz que reivindica la importancia de combatir el racismo y el sexismo en su país. También fue directora del Centro de Estudios y Promoción Afroperuano de Lima, LUNDU, una fundación que lucha por el reconocimiento de la historia e importancia negra a la cultura peruana. El periódico Americas Quaterly, en artículo firmado por Lance Steagall, registra que:

El activismo de Carrillo se extiende más allá del fortalecimiento de la comunidad afroperuana. Ella quiere que la rica cultura afro del Perú sea reconocida como parte de la identidad nacional, algo que dice desde hace mucho tiempo. 'Cuando vienes a Perú, a diferencia de Colombia o Brasil, no encuentras nada [que represente la cultura afroperuana]', dice. 'Encontrarás música tradicional, pero no pinturas ni esculturas's. (STEAGALL, 2009, s.p)

Luego, hay en la obra de Zegarra una dedicación a la cultura negra de su país, una búsqueda de construcción de una hermandad afro-peruana que represente artísticamente la contribución negra al país. Y el libro a que me refiero aquí es un encuentro de voces, de memorias ancestrales, un puente entre el continente africano imaginado por los/las descendientes afroamericanos/as y la cultura del otro lado del atlántico, donde las ancestras a que se refiere Zegarra tuvieron que reinventarse para seguir vivas. De manera que accedieron a matarnos, pero "acordamos no morir"5 (EVARISTO, 2015, p. 99), la icónica frase de la autora brasileña parece describir perfectamente el

3 En el original: “As mulheres negras assistiram, em diferentes momentos de sua militância, à temática específica da mulher negra ser secundarizada na suposta universalidade de gênero. Essa temática da mulher negra invariavelmente era tratada como subitem da questâo geral da mulher". (Traducción mía del portugués)

4 En el original: "Carrillo's activism extends beyond strengthening the Afro-Peruvian community. She wants Peru's rich Afro culture to be recognized as part of the national identity, something she says is long overdue. 'When you come to Peru-unlike Colombia or Brazil-you don't find anything [that represents Afro-Peruvian culture],' she says. 'You'll find traditional music, but you won't find paintings or sculpture"'. (Traducción mía del inglés)

5 En el original: "A gente combinamos de năo morrer". (Traducción mía del portugués) 
sentimiento y el procedimiento de Zegarra.

El título Unícroma no puede ser tomado al azar. Formado de la unión de dos términos uni + croma se refiere a 1) uni, unión entre las y los afrodescendientes de Perú en torno a la cultura ancestral y de las vivencias, marcas del feminismo negro que se interesa en debatir a partir de la realidad de los traumas racistas de mujeres marginadas; y 2) croma, del griego chróma, color. O sea, es la recorrida de historias que tienen en común el color de los personajes como elemento importante a la comprensión, y, a la vez, refuerzo de la idea de unión a partir de las experiencias raciales que comparten.

En definitiva, Unícroma está en el conjunto de trabajos que Zegarra promueve en muchas líneas con el objetivo de que, con el arte, la performance y la literatura, produzca discursos también políticos. En una entrevista, disponible en YouTube, ella define su producción así:

\begin{abstract}
Yo trabajo desde muchas líneas, pero principalmente mezclando la política con el arte. El arte como una manera de transformación social, como una manera de cambiar la historia de vida de nuestras comunidades. Trabajo muchos proyectos donde utilizo la poesía, la música, el tejido, con proyectos educativos de largo plazo, por ejemplo, con grupos de gente con las cuales se puede trabajar por cinco, seis o siete años, para poder ver este cambio, esta transformación. (ZEGARRA, 2021, s.p, énfasis mío)
\end{abstract}

En este artículo me dedico a leer de modo especial los versos de "Juguemos en la jungla", a ver cómo el yo lírico, una mujer negra, convoca otra mujer, blanca, a que esta pueda darse cuenta de los problemas de un feminismo universal, estándar, que no se dedique a las particularidades de la vivencia de las mujer negras. Es decir, las especialidades de un feminismo que debate el género atravesado por raza y clase, como lo piensan Lugones (2011), Carneiro (2011) y Mohanty (2008).

La poesía se estructura como un diálogo en que, no al azar, se lee solamente la voz del yo lírico, en que éste reflexiona tras los cuestionamientos sobre las pautas del feminismo, o sea, como si fuera una provocación impuesta por otras voces ajenas. Es importante señalar también que esa dirección que toma el yo lírico es una inversión de la lógica de los movimientos de mujeres burguesa que tienden a silenciar a las mujeres negras, tercermundistas y pobres (cf. Mohanty, 2008), debido a una pretensa unicidad, además sirve a que se dedique a las pautas raciales que atraviesan la experiencia de su mujeridad.

Ya por el título se puede preguntar quién compone el plural del verbo 'jugar', es decir, a quien se refiere el yo lírico. La respuesta que podría tardar toda la poesía, el yo lírico parece contestar enseguida, en la dedicatoria. El título, así, es antes una invitación a las mujeres blancas a que escuchen lo que las negras tienen para decir.

\title{
JUGUEMOS EN LA JUNGLA
}

\author{
Para nosotras las feministas (ZEGARRA, 2015, p. 6)
}

O sea, la lectora o el lector, en suma, al leer el título puede preguntarle al yo lírico, ¿a quién se dedica la invitación al juego?, ¿de qué juego se trata?, ¿cuáles son las reglas? Y ese podría ser el mote de la poesía, pero, la opción está, justamente, en subvertir esa posibilidad, respondiendo a la pregunta implícita en la primera línea, y seguir componiendo una poesía en que contraponga las distintas experiencias de las mujeres a 
partir del elemento raza.

El yo lírico, pues, compone una voz que literariamente demuestra que, aunque estén bajo el mismo sistema de opresión, la vivencia de mujeres blancas y negras no son intercambiables en sociedades racistas, no son iguales. La implícita pregunta retórica, así, esconde no solamente la invitación a la escucha, sino también una reflexión sobre las prácticas y deseos que componen la lucha del feminismo negro.

Se debe agregar también que el título se compone como en un juego infantil a partir del cual la voz central del poema resignifica y enseña a sus interlocutoras - las feministas blancas - el espacio ajeno, salvaje, de la jungla en que fue puesta por la organización racista y segregadora de la sociedad. Es precisamente de la 'jungla' que pretende hablar, de donde va a contar su vida, un espacio distinto de lo que ocupan las mujeres blancas en el imaginario burgués colonizador y racializado. De ahí que la invitación surge como una llamada a un espacio poco conocido o habitado por esas interlocutoras.

A ese respeto, a lo largo del poema nos damos cuenta de que la voz lírica pretende establecer ya con el título un escenario muy peculiar alejándose de la casa, de "lo doméstico" en que habita la mujer blanca, aunque sea conocido por la negra. Ese desplazamiento lleva a las interlocutoras a un espacio muy lejos, casi siempre borrado del horizonte de expectativas de las mujeres blancas burguesas. En síntesis, es una invitación a que la mujer blanca deje su hogar hacia la "jungla" lejana, la historia, los traumas y la rutina de la mujer negra.

Si el título impone una pregunta implícita, los primeros versos son efectivamente cuestionadores e, incluso, exponen un tono bien provocativo, incitando, estimulando el pensamiento feminista más estándar, blanco, europeo a pensarse como parte del sistema opresor.
¿A qué clase de mujer te refieres?
tú, ¿̇mujer?
¿el significado de lo "doméstico" es el mismo para
ambas?
Te advierto. (ZEGARRA, 2015, p. 6, énfasis suyos)

Los términos en énfasis corroboran con el tono de esa voz lírica a que me refiero. Cuando dice que les advierte - a las feministas -, el yo lírico está como que preparando el escenario en que seguirá explicitando la necesidad de repensar el feminismo para pautas menos burguesas, que no quieran privilegiar un sujeto mujer universal, hegemónico, occidental, del norte global (Mohanty, 2008).

Otro punto es la concepción de la idea de lo "doméstico" que, conforme se observa aquí tiene un significado distinto a depender de quien lo utiliza: para la mujer blanca es el espacio de donde cuestiona su vida como ama de casa, su encarcelamiento como pareja de alguien; mientras que para la mujer negra es un espacio que no pudo ocupar, ya que nunca ha podido gozar el derecho de quedarse en su casa, con sus hijos e hijas, tuvo que salir y trabajar siempre. En otras palabras, la mujer negra no pudo ocupar su espacio doméstico, el de su casa, sin embargo, ha ocupado lo doméstico de las mujeres blancas. En este sentido, no se puede olvidar que a esta actividad se denomina trabajo doméstico, como si estas mujeres que ahí trabajan solamente existieran en este contexto, en la casa 
de alguien, como si fueran parte de los muebles de una casa que no les pertenece.

La estrofa siguiente discute este punto de vista distinto y me parece muy feliz que el camino con que comienza el texto sea el del ambiente de la domesticidad, poniéndola en jaque, de ahí que perturba e inquieta la supuesta agenda de un feminismo universal. Mientras las mujeres blancas están cuestionando su domesticidad, buscando los espacios públicos en la defensa de igualarse en derechos con su semejante hombre blanco; las mujeres negras, según el yo lírico, siempre estuvieron en las calles, pues, su doméstico nunca les perteneció, ya que muy temprano, desde hace muchos tiempos tuvieran ellas que dejarlo, como se observa enseguida.

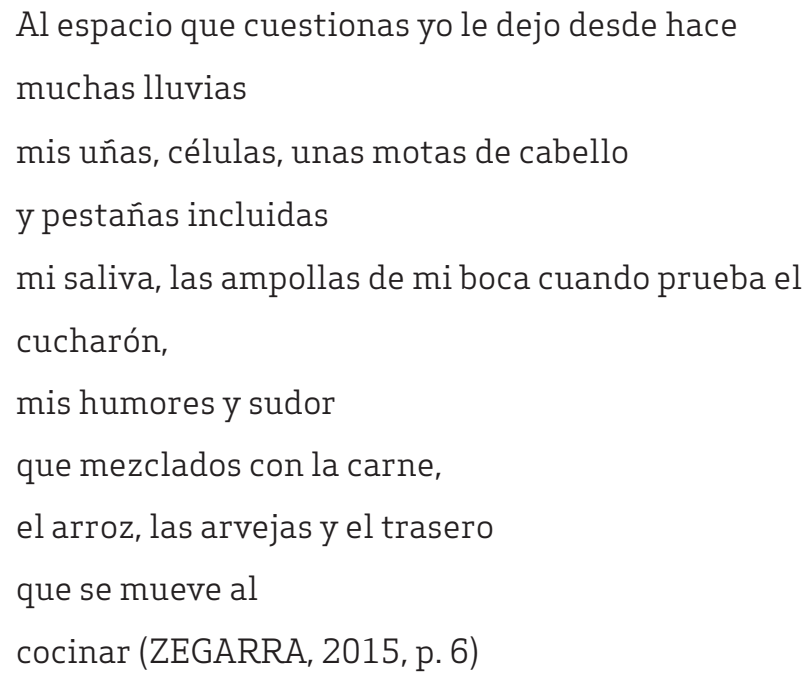

Irónicamente, el espacio doméstico donde trabajan las mujeres negras, para donde tuvieron que seguir, donde dejan su vida, donde la pierden, es de donde quieren las blancas evadirse. Queda claro que las experiencias en este espacio son muy distintas. Hay aquí una jerarquía que el yo lírico registra entre esas dos personajes en el mismo ambiente, ya que, para que una pueda luchar por sus ideales y partir a otros lados de la esfera pública, la otra debería quedarse con el cuidado doméstico. Aunque, obviamente, no esté en el movimiento feminista burgués tales discursos, el yo lírico es muy sagaz al describir las oposiciones que la referida palabra asume según quien la utiliza.

Debe registrarse también el modo metonímico, nada sutil que utiliza el yo lírico para aclarar que su cuerpo en la economía burguesa y racista pertenece a la casa de la mujer blanca y, por extensión, a la mujer blanca. Son sus "uñas, células, unas motas de cabello y pestañas incluidas". Luego, la domesticidad de la negra la blanca la quita, así como su cuerpo.

La sociedad descrita por Mónica Zegarra (2015) en estos versos iniciales presenta una realidad común a muchas mujeres negras en diversas sociedades occidentales, incluso la latinoamericana, que mantiene bajo un ideal con reminiscencias esclavistas estas mujeres subyugadas. Sin embargo, es, a la vez, un acto de sedición, o sea, de resistencia al sistema racista, clasista y burgués traerlos a la poesía, una vez que está escrito, registrado, por una voz que históricamente fue callada, que no pudo decir de sus traumas, los cuales siguieron desde "hace muchas lluvias" olvidados. Como diría Spivak (1998), es el sujeto subalterno diciendo e imponiendo su voz, evitando que otros sujetos se apropien de su discurso o lo silencien del todo. ¿Será que el sujeto 
subalterno no puede hablar? Zegarra (2015) demuestra que sí, puede, y cuando habla nos pone a pensar, produciendo cambios en la materialidad de lo que se llamó literatura en el occidente.

La voz de Mónica Zegarra (2015), así, resuena en muchas otras voces latinoamericanas de mujeres negras que tomaron la palabra y pudieron, una vez leídas / escuchadas, transformarse en dueńas de un discurso que funciona como arma contra la explotación silenciosa de las cocinas en que sus cuerpos "mezclados con la carne" se movieron para cocinar. No solamente para cocinar, como se sabe, pero también para el usufructo sexual de los hombres blancos, señores de esas casas.

En este sentido, traigo también como una comparación discursiva la poeta afro brasileña Cristiane Sobral, que, en una de sus poesías más conocidas, parece dar un paso más adelante, con un yo lírico oponiéndose a seguir trabajando en el espacio privado / doméstico de la casa de otras mujeres.

Năo vou mais lavar os pratos.

Nem vou limpar a poeira dos móveis.

Sinto muito. Comecei a ler. Abri outro dia um livro

e uma semana depois decidi.

Nâo levo mais o lixo para a lixeira. Nem arrumo

a bagunça das folhas que caem no quintal (SOBRAL, 2000, s.p)

Retomando Zegarra (2015), hay un momento del texto en que el yo lírico llama nuevamente esa otra voz, aparentemente cambiando el tono, para algo menos contundente, más pacífico. Puede parecer en una primera lectura que hay aquí un arrepentimiento de las palabras más duras dichas anteriormente, o una búsqueda de formas más sutiles para no melindrear la audiencia, la mujer blanca, o aún, una subordinación explícita provocada por los espacios jerárquicos que ocupan socialmente.

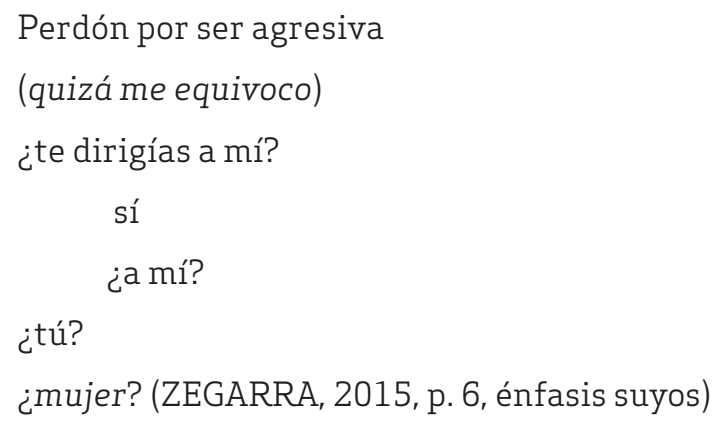

A pesar de toda esa suposición pertinente, me parece que si así fuera - un simple cambio de tono -, el yo lírico correría el riesgo de cambiar muy bruscamente la dirección que viene tomando hasta este punto, perdería la ironía constante y la coherencia interna del texto. Así siendo, creo que sea más una estrategia de cortesía con el receptor del discurso para introducir un viaje histórico sobre la sobrevivencia negra y el borramiento en el movimiento feminista, quizás más sistemático, aunque panorámico, como el género poesía lírica suportaría. Además, destaco el énfasis de la voz lírica como recurso irónico que le otorga soporte a esa lectura que propongo.

Antes que pasemos al panorama mencionado, quiero destacar cómo el yo lírico 
se refiere a la interlocutora como "mujer" constantemente. Si tomamos lo escrito por Lugones (2011), este referente en el mundo colonial fue dedicado solamente a la hembra del 'hombre', éste también blanco, europeo, burgués. De ahí que cuando dice “¿tú? / ¿mujer?", con el recurso del énfasis, está manejando el lenguaje, el idioma impuesto por el colonizador y las categorías creadas por él, para decir que ella, la que escribe el poema, bajo la lógica de ese sistema opresor, de hecho, no sería una mujer. Es antes, cualquier cosa de no humano. Teniendo en cuenta que el feminismo universal pauta la lucha de las mujeres, el yo lírico, una vez más de modo muy irónico, puntea la necesidad de repensarlo, de lo contrario nunca su voz será escuchada por el movimiento.

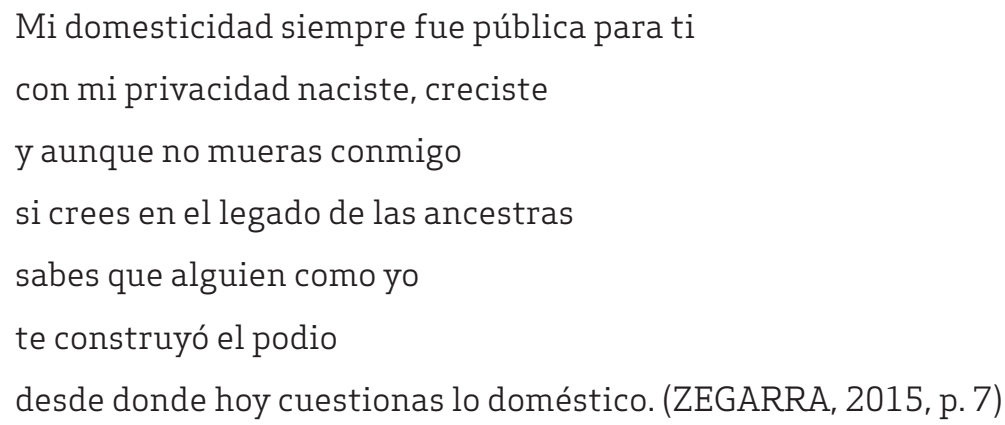

Si todavía existía cualquier duda al respecto de las distinciones entre las mujeres negras y las blancas, aquí el yo lírico la deshace. En los últimos versos de la estrofa, esboza que las mujeres blancas pudieron construir un feminismo con una retórica de libertad e igualdad entre hombres y mujeres porque la negra estuvo siempre dándoles soporte, "el podio" a que se refiere ${ }^{6}$. Zegarra (2015) expone la necesidad de echar una mirada específica hacia los diferentes ejes que cruzan la vida de las mujeres negras y les impone este lugar de sustentáculo a las blancas del movimiento feminista universal, una mirada hacia las prácticas sociales que constituyen diferentes papeles en el desarrollo económico y social a distintas mujeres.

A ese respeto, Mohanty (2008) es categórica:

Las prácticas que caracterizan el estatus y el papel que juegan las mujeres varían según la clase social. Las mujeres están constituidas como mujeres a través de una complicada interacción entre clase, cultura, religión y otras instituciones y marcos de referencia. No son "mujeres" - un grupo coherente - simplemente en función de un sistema económico o una política particular. El reduccionismo de semejantes comparaciones transculturales resulta en la colonización de los elementos específicos de la existencia cotidiana y de las complejidades de los intereses políticos que representan y movilizan a las mujeres de distintas culturas y clases sociales. (MOHANTY, 2008, p. 11)

Al pensar la mujer en términos absolutos como si fuera siempre una sola realidad, una sola posibilidad en cualquier contexto, el movimiento feminista acaba por

6 Aunque en este artículo, basado en el poema de Zegarra, se evidencie el rol de las mujeres negras en las casas burguesas y la relación con las mujeres blancas, no se puede olvidar la fuerte presencia de mujeres indígenas en puestos de trabajo doméstico muy semejantes en la América Latina. A ese respeto, sugiero como ejercicio de comparación, la película mexicana Roma (2018), del director Alfonso Cuarón. 
colaborar, en cierta medida, con el sistema opresor a que pretende combatir, puesto que el discurso universal silencia realidades atravesadas por otros sistemas de subordinación, que se basan en una lógica colonial como la raza y las clases, como hemos dicho a lo largo de este trabajo. Y en ese sentido, son tan autoritarios y coloniales como su propio opresor.

Ochy Curiel (2010) ya teorizó sobre esa diferencia al defender un feminismo en intersección con otras matrices de dominación:

Este feminismo del que hablo se piensa y repiensa a sí mismo en la necesidad de construir una práctica política que considere la imbricación de los sistemas de dominación sexista, racial, heterosexista y capitalista, porque considerar esta matriz de dominación, (Collins, 1999) es lo que otorga al feminismo una visión radical. (CURIEL, 2010, p. 71)

El feminismo negro y decolonial, a su vez, es justamente ese paseo a la jungla propuesto por Zegarra (2015), una ida al desconocido que le propone a su audiencia la voz lírica. Un paseo en que se presente otras formas de dominación y que, a depender de la estrategia discursiva de esa mujer negra, ora puede ser más dura e incómoda, ora más sutil a la mujer blanca burguesa, pero siempre necesario.

El poema de Zegarra (2015) sigue oponiéndose a uno de los signos más rutinariamente asociados al femenino, la debilidad. ¿Será que le correspondería a la mujer negra ese lugar débil?
Yo nunca fui débil,
trabajé fuera del hogar
500 años antes de que tú lo pensaras
no me desmayaba por las emociones fuertes
tampoco vivía para educar a mis hijos
a mí siempre me los quitaban. (ZEGARRA, 2015, p. 7)

Como en un proceso de metalenguaje, la crítica aquí recae también sobre el estereotipo de mujer que la literatura canónica ayudó a conformar en siglos de producciones que siempre, o casi siempre, relegaron a los personajes femeninos una debilidad, una necesidad del otro masculino que les ayudara, les salvara, sea de brujas en los cuentos infantiles, sea con el matrimonio en historias desde la Edad Media, pasando por los romanticismos hasta la modernidad.

Son, al fin y al cabo, mayoritariamente personajes cuyo único objeto es el matrimonio, una familia heterosexual, institución sagrada en la óptica burguesa para la felicidad plena de esas mujeres que rápidamente se convertirían en madres. Una vez más un punto importantísimo a ser debatido: la maternidad. Ya se sabe contemporáneamente que la maternidad es también una construcción social (cf. Batinder, 1985), pero tal construcción no les alcanzó a las mujeres negras, como seńala bien Zegarra al decir que "tampoco vivía para educar a mis hijos / a mí siempre me los quitaban" (2015, p. 7). Angela Davis (1983) asevera que:

La exaltación ideológica de la maternidad, tan popular como fue durante el siglo XIX, no se extendió a las esclavas. De hecho, a los ojos de los esclavistas, las esclavas 
no eran madres en absoluto; eran simplemente instrumentos que garantizaban el crecimiento de la mano de obra esclava. Eran vientres reproductores: animales, cuyo valor monetario podía calcularse con precisión en términos de su capacidad para multiplicar su número. (DAVIS, 1983, p. 10) 7

Todavía a respeto de ese tramo de la poesía, el yo lírico dialoga con el clásico discurso de la feminista negra estadunidense Sojouner Truth, en que ésta, en una conferencia de mujeres, en 1851, en el estado de Ohio, se atrevió a hablar, siendo la única negra, contraponiendo lo que había escuchado que sería lo femenino con su propia vivencia hasta aquel momento. Truth, hija de sujetos esclavizados, en los EE. UU del siglo XIX, aún más racista, toma la voz, y de su discurso improvisado, comienza a diversificar el referente mujer al cuestionar ¿no soy yo una mujer?, y se convierte en una voz poderosa a los estudios feministas negros desde entonces.

Los caballeros dicen que las mujeres necesitan ayuda para subir a las carretas y para pasar sobre los huecos en la calle y que deben tener el mejor puesto en todas partes.

¡Pero a mí nadie nunca me ha ayudado a subir a las carretas o a saltar charcos de lodo o me ha dado el mejor puesto! y ¿Acaso no soy una mujer? ¡Mírenme! ¡Miren mis brazos! ¡He arado y sembrado, y trabajado en los establos y ningún hombre lo hizo nunca mejor que yo! Y ¿Acaso no soy una mujer? ¡Puedo trabajar y comer tanto como un hombre si es que consigo alimento-y puedo aguantar el latigazo también! Y ¿Acaso no soy una mujer? Parí trece hijos y vi como todos fueron vendidos como esclavos, cuando lloré junto a las penas de mi madre nadie, excepto Jesús Cristo, me escuchó y ¿Acaso no soy una mujer? (TRUTH, 2016, s.p)

Posteriormente, en la poesía de Zegarra, la voz lírica trata de la violencia que sufren cuerpos negros con mayor frecuencia que la sufrida por cuerpos blancos. Su estrategia aquí parece resonar la suma de violencias que aquel cuerpo soportó a lo largo de los siglos. Además, resalta, que a la violencia de género sufrida por ella se añade una más específica, decurrente de la raza y de la clase.

Sé que hay asesinos sueltos que te matan,

pero hace tiempo que lo hacen conmigo

y ¿tú? ¿no eres más que mujer?

¿algo más divertido? ¿tormentoso o apasionado?

Siempre quieres que juguemos en el bosque

territorio a que estás acostumbrada.

Loba

(¿qué estás haciendo?)

Loba (ZEGARRA, 2015, p. 7-8)

7 En el original: "Ideological exaltation of motherhood-as popular as it was during the nineteenth century-did not extend to slaves. In fact, in the eyes of the slaveholders, slave women were not mothers at all; they were simply instruments guaranteeing the growth of the slave labor force. They were "breeders"-animals, whose monetary value could be precisely calculated in terms of their ability to multiply their numbers" (Traducción mía del inglés) 
Cuando, con su ya conocida ironía, pregúntale a la mujer blanca si ella no sabe ser nada "más divertido" que mujer, evidencia que además de la violencia de género que comparten, la negra sufre el racismo y la violencia de clase, no raro. No olvidemos que ella siempre ha trabajado porque tuvo que hacerlo, su clase social se lo impone bajo pena de no vivir, ya que otras posibilidades de existencia se les son prohibidas. Está puesto como si dijera que sufrir por ser mujer le parece poco si comparado con el sufrimiento que vive todos los días de su vida.

Nuevamente trae la cuestión de los territorios que estos cuerpos ocupan socialmente. Mientras ella está vigilada y apartada, segregada sea en la cocina de las casas de la burguesía, sea en la jungla, lejos de la mirada blanca, las mujeres blancas estarían en un bosque, símbolo adecuado a la metáfora de "lobas" con que se refiere a su interlocutora. El juego que propone el yo lírico es precisamente desestabilizar esa seguridad que la mujer blanca tiene sobre el territorio que habita, que bien conoce, a "que está[s] acostumbrada" (ZEGARRA, 2015, p. 8).

El tropo siguiente de esa relación que la teoría del feminismo negro y decolonial ya trató y Zegarra (2015) literariamente la escribe está en diálogo con lo que Lugones (2011) llama de lectura del locus fracturado, o sea, la posibilidad de manejo de las feministas decoloniales desde dentro del ordenamiento burgués colonial que persiste en la actualidad. En otros términos, es darse cuenta de que la resistencia a los traumas impuestos por la colonización y por la decolonialidad, al racismo y al clasismo sumados al sexismo pasa por nombrarlos, sacarlos del limbo identitario en que fueron puestos, y pasa todavía por exigir que las diferencias entre la mujer blanca y la negra sean muy bien observadas, que la identidad negra esté viva.

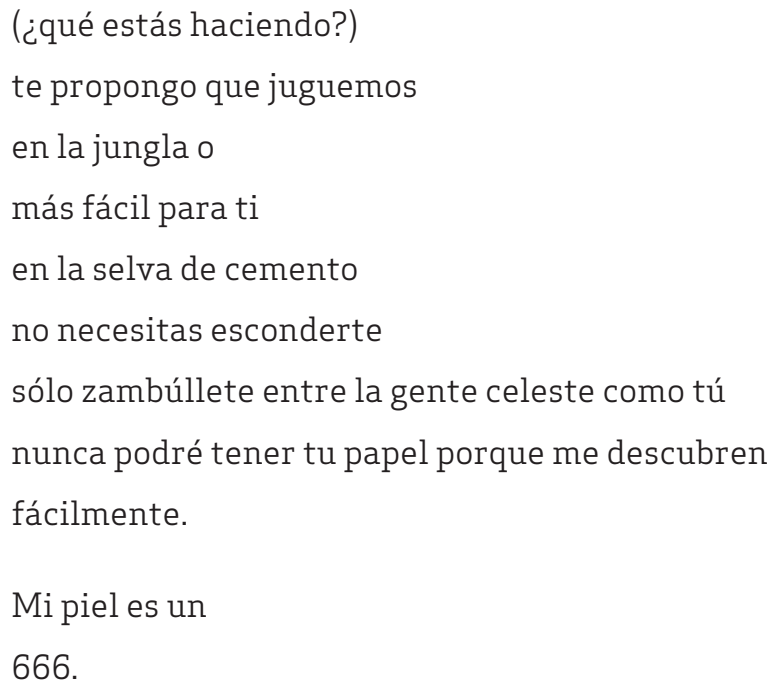

Aunque llame al principio del texto la mujer blanca a que jueguen en la jungla, la mujer negra acepta que el juego se de en la "selva de cemento" (ZEGARRA, 2015, p. 9), el territorio de la mujer blanca, pero, de cierto modo, también donde vive esa mujer negra, disminuida en la cocina. Ese encuentro es el que produce la colonialidad del género a que se refiere Lugones (2011), es de ahí que podrá mejor exponer que el color de su 
piel le otorgó una vivencia particularizada del género, puesto que jamás podrá hacerse pasar por la mujer blanca, o sea, acceder a su puesto.

Comprendamos, sin embargo, que el yo lírico parece dialogar con la blanquitud como un sistema de posicionamiento social que encuentra en el color de la piel el referente social, o sea, al decir que nunca podrá tener el papel de la blanca, no se refiere a los trazos europeos o fenotípicos de esa población y sus descendientes, pero, a la lectura social que adquieren las personas que los tienen.

La colonialidad del género me permite comprender la imposición opresiva como una interacción compleja de sistemas económicos, racializantes y generizantes, en los cuales cada persona en el encuentro colonial puede ser vista como un ser vivo, histórico, plenamente descrito. Como tal quiero comprender a quien se resiste como oprimido por la construcción colonizadora del locus fracturado. [...] Al enfocar a quien se resiste en la diferencia colonial mi intención es develar lo que había sido oscurecido. (LUGONES, 2011, p. 110)

Por fin, recurre a una imagen que reproduce la lectura social que recae sobre el cuerpo negro en la sociedad de cemento a que se había referido anteriormente. Mismo en un área urbana, de transito libre, los cuerpos negros siguen vigilados, no pueden ocupar espacios otros que no los previamente destinados a su vivencia. Es como si hubiera una memoria, una expectativa de que estos cuerpos estuvieran resignados a limitarse a ciertas posibilidades muy específicas. Por ejemplo, en el ficticio restaurante a que se refiere el yo lírico ${ }^{8}$, la mujer negra no estaría para ser servida, sino para servir, siguiendo una memoria y un lugar específico.

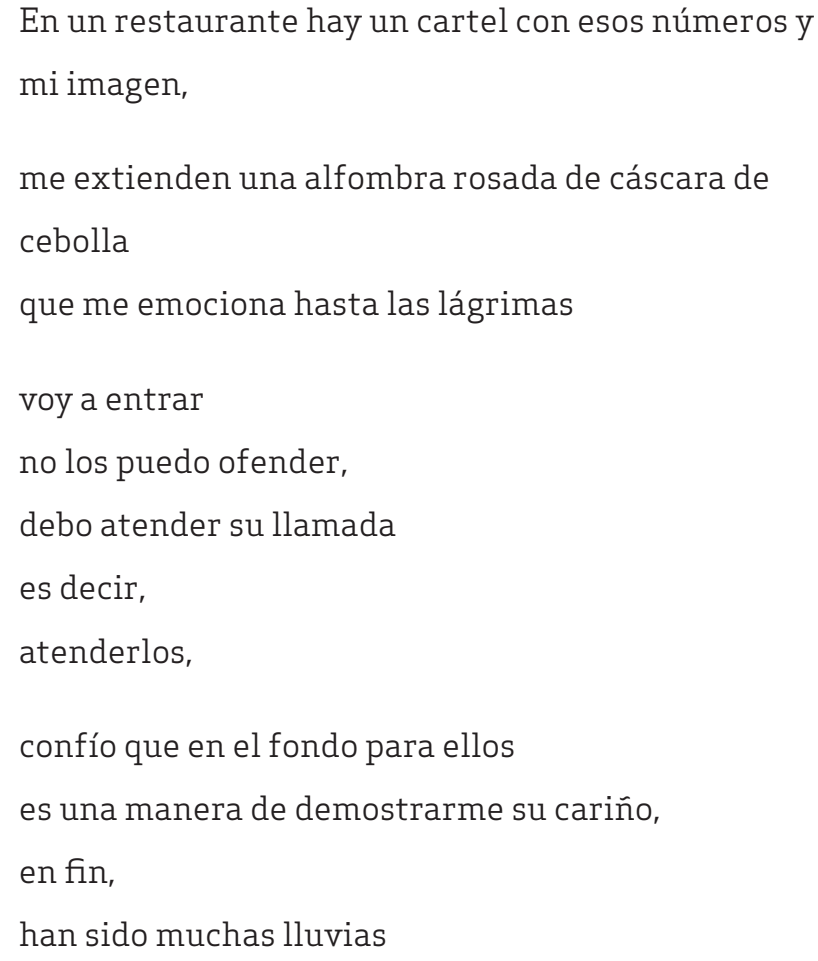

8 Como ejercicio de comparación, sugerimos el videoclip del rapero y cantante brasileño Emicida, Eminencia Parda (2019), con escenas muy semejantes a la que propone el yo lírico en este tramo del poema. 


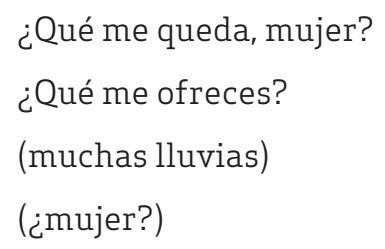

El lugar específico a que nos referimos no es necesariamente el de la cocina, pero el del cuidado, espacios que las ancestras de la voz lírica ya ocuparon. En este sentido, podemos concluir que la colonialidad mantiene viva la separación dicotómica entre cuerpos a partir de la raza. Ser negra, en este sentido, más que ser referente de un color, es vivir bajo una estrechez de clasificación.

Debe registrarse también que la voz lírica señala que la subordinación que no le permite otro comportamiento cualquier que pueda ofender, todo lo contrario, debe "atender [la] llamada", frente a la alfombra, pero de cáscaras de cebolla y llorar, no por emocionarse o por su emoción ser valorada, pero por lidiar con la cebolla, el trabajo. Y sigue, una vez más irónicamente trazando este escenario, trayendo nuevos personajes al final del poema, los cuales, siempre la han tratado de esa forma, pero como demostración de "cariño", al fin y al cabo, fueron muchos años lidiando con esta realidad.

A la mujer negra está la determinación de estos espacios y una función social, que atraviesa la vivencia, que se reproduce hace muchas lluvias, es decir, mucho tiempo, de esa manera, viene anteriormente a la existencia de ese personaje que construyó la poesía.

El poema, de ese modo, es un arma, como ya dije, contra la marginalización de este sujeto social en sociedades racializadas, pero, a la vez, también sirve como un recorrido de la historia de ese grupo social, de las ancestras que tuvieron que salir de África, de su 'jungla', o, mejor dicho, territorio original, y contemporáneamente de sus descendientes que siguen viviendo bajo un sistema de opresión muy semejante al de la esclavitud.

La negra, pues, es un locus social, ya que el sujeto negro lo es debido a una herencia colonial que tuvo en la raza y en el color de la piel la marca indeleble de clasificación y jerarquía social. Pero, por otro lado, como Kabengele (2020) pontea, el ser negra "no nace del simples hecho de tomar consciencia de la diferencia de pigmentación entre blancos y negros o negros y amarillos. [...] se refiere a la historia común que liga de una manera o de otra todos los grupos humanos que la mirada del mundo occidental 'blanco' reunió bajo el nombre de negros" (KABENGELE, 2020, p. 19). En este sentido, el yo lírico convoca todo el tiempo a lo largo de la poesía esa herencia de sus ancestras, silencia las otras voces, blancas, cuenta desde su perspectiva la historia, y retoma irónicamente los espacios segregados que tuvieron que ocupar.

Al fin y al cabo, al contar su historia y de sus ancestras, Mónica Carrillo Zegarra toma la voz de un discurso que siempre quiso definirla, segregarla, poner su identidad bajo términos hegemónicos y los subvierte, ironiza el borramiento social y político que las negras sufrieron incluso por parte del movimiento feminista estándar. En síntesis, al tomar la palabra, se aproxima de lo que Victoria Santa Cruz, en el poema transcrito al comienzo de ese artículo dice, determina su negritud y se adueña de esa historia; el grito de negra, así, viene ahora de su conocimiento, no se trata, pues, de una voz ajena, pero de su poder de nombrarse, siendo el yo del discurso, nunca más el otro. 


\section{REFERENCIAS}

BADINTER, Elizabeth. 0 amor conquistado. Traduçăo de Waltensir Dutra. Rio de Janeiro: Nova Fronteira, 1985.

BENJAMIN, Walter. Obras escolhidas. Vol. 1. Magia e técnica, arte e política. Ensaios sobre literatura e história da cultura. Trad. Sérgio Paulo Rouanet. São Paulo: Brasiliense, 2012, p. 241-252.

BELL, Hooks. Feminist Theory - from Margin to Center. Boston: South End Press, 1984.

CARBY, Hazel V. Mujeres blancas, jescuchad! El feminismo negro y los límites de la hermandad femenina. In: JABARDO, Mercedes (ed.). Feminismos negros - Una antología. Madrid: Traficantes de Sueños, 2012, p. 208-242.

CARNEIRO, Sueli. Racismo, sexismo e desigualdade no Brasil. Săo Paulo: Selo Negro, 2011. CURIEL, O. Hacia la construcción de un feminismo descolonizado. In: ESPINOZA, Y. (Dir.). Aproximaciones éticas a las prácticas teóricas políticas del feminismo latinoamericano, tomo I. Buenos Aires: En la Frontera, 2010, p. 69-76.

DAVIS, Angela. Women, race and class. Nova York: Randon House, 1983.

EVARISTO, Conceiçấo. A gente combinamos de nâo morrer. In.: Olhos d'Água. Rio de Janeiro: Pallas, 2015.

GONZALES, Lélia. Por um feminismo afro-latino-americano. Revista Isis Internacional, Santiago, v.9, p. 133-141, jun. 1988.

KABENGELE, Munanga. Negritude - Usos e sentidos. 4 ed. Belo Horizonte: Autêntica, 2020.

LUGONES, María. Hacia un feminismo descolonial. La manzana de la discordia, JulhoDezembro, Ano 2011, Vol. 6, No. 2: 105-119.

MOHANTY, Chandra Talpade. Bajo los ojos de occidente. Academia Feminista y discurso colonial. In: NAVAZ, Liliana Suárez; HERNÁNDEZ, Aída (org.). Descolonizando el Feminismo: Teorías y Prácticas desde los Márgenes. Madrid: Cátedra, 2008. Disponível em: <https://www.feministas.org/IMG/pdf/articulo_libro_descolonizando_el_feminismo-.pdf.> Acesso em maio de 2021.

MOHANTY, Chandra Talpade. "Sob os olhos do Ocidente: estudos feministas e discursos coloniais". In: BRANDÂO, Izabel et al. (Orgs.). Traduçóes da cultura. Perspectivas críticas feministas (1970-2010). Florianópolis: Editora Mulheres/EdUFAL, 2017.

QUIJANO, Walter.Colonialidad del poder, eurocentrismoy América Latina.In:Cuestiones y horizontes - de la dependencia histórico-estructural a la colonialidad/descolonialidad del poder. Buenos Aires: CLACSO, 2014, p. 776-832.

SOBRAL, Cristiane. Cadernos negros 23: poemas afro-brasileiros, 2000.

SPIVAK, Gayatri. Chakravorty. ¿Puede hablar el sujeto subalterno? Orbis Tertius, 3 (6), 175-235. In: Memoria Académica. 1998. Disponível em: <http://www.fuentesmemoria. fahce.unlp.edu.ar/art_revistas/pr.2732/p r.2732.pdf.>. acesso em abril de 2021 
STEAGALL, Lance. Civic Innovator: Monica Carrillo, Perú. Americas Quaterly, 2009. Disponível em: <https://www.americasquarterly.org/fulltextarticle/civic-innovatormonica-carrillo-peru/>. Acesso em: maio de 2021.

TRUTH, Sojouner. ¿No soy yo una mujer?. 2016. Disponível em: 〈https://tribunafeminista.elplural.com/2016/07/sojourner-truth-no-soy-yo-una-mujer/>. Acesso em maio de 2021.

UNIVERSIDADE LIVRE FEMINISTA. Me gritaram negra, poema de Victoria Santa Cruz. Disponível em: <http:/feminismo.org.br/me-gritaram-negra-poema-de-victoria-santacruz/>. Acesso em maio de 2021.

ZEGARRA, Mónica Carrillo. Unícroma - Selección de poemas. Instituto Cervantes, 2015. Disponível em: <http://www.cervantesvirtual.com/obra/unicroma-seleccion-de-poemas/ >. Acesso em abril de 2021.

ZEGARRA, Mónica Carrillo. Entrevista. Disponível em: <https://www.youtube.com/watch?v=pOJZSrNVU8U> Acesso em maio de 2021. 